\title{
Inadequate Timing Limits the Benefit of Antenatal Corticosteroids on Neonatal Outcome: Retrospective Analysis of a High-Risk Cohort of Preterm Infants in a Tertiary Center in Germany
}

\author{
Schlechtes Timing reduziert den Nutzen von antenatalen \\ Kortikosteroiden für das neonatale Outcome: eine retrospektive \\ Analyse einer Hochrisikogruppe von Frühgeborenen in einem \\ deutschen Perinatalzentrum Level 1
}

(우요요요

Authors

Richard Biedermann ${ }^{1}$, Ekkehard Schleussner ${ }^{2}$, Angela Lauten ${ }^{2}$, Yvonne Heimann ${ }^{2}$, Thomas Lehmann ${ }^{3}$, Hans Proquitté $^{1}$, Friederike Weschenfelder ${ }^{2}$

Affiliations

1 University Hospital Jena, Unit Neonatology, Department of Paediatrics, Jena, Germany

2 University Hospital Jena, Department of Obstetrics, Jena, Germany

3 University Hospital Jena, Institute of Medical Statistics and Computer Science, Jena, Germany

Key words

antenatal corticosteroids, preterm birth, VLWB, perinatal outcome, respiratory distress syndrome

\section{Schlüsselwörter}

antenatale Kortikosteroide, Frühgeburt, VLWB, perinatales Outcome, Atemnotsyndrom des Frühgeborenen

\section{received}

accepted after revision

\section{Bibliography}

Geburtsh Frauenheilk 2022; 82: 317-325

DOI 10.1055/a-1608-1138

ISSN 0016-5751

(C) 2022. The Author(s).

This is an open access article published by Thieme under the terms of the Creative Commons Attribution-NonDerivative-NonCommercial-License, permitting copying and reproduction so long as the original work is given appropriate credit. Contents may not be used for commercial purposes, or adapted, remixed, transformed or built upon. (https://creativecommons.org/licenses/by-nc-nd/4.0/)

Georg Thieme Verlag KG, Rüdigerstraße 14,

70469 Stuttgart, Germany
Correspondence

Dr. Ekkehard Schleußner

University Hospital Jena, Department of Obstetrics

Am Klinikum 1, 07747 Jena, Germany

ekkehard.schleussner@med.uni-jena.de

\section{ABSTRACT}

Introduction A common problem in the treatment of threatened preterm birth is the timing and the unrestricted use of antenatal corticosteroids (ACS). This study was performed to evaluate the independent effects of the distinct timing of antenatal corticosteroids on neonatal outcome parameters in a cohort of very low (VLBW; 1000-1500 g) and extreme low birth weight infants (ELBW; <1000 g). We hypothesize that a prolonged ACS-to-delivery interval leads to an increase in respiratory complications.

Materials and Methods Main data source was the prospectively collected single center data for the German nosocomial infection surveillance system (KISS) between 2015 and 2018. Multivariate regression analysis was performed to determine independent effects of the ACS-to-delivery interval on the need for ventilation, surfactant or the occurrence of bronchopulmonary dysplasia, neonatal sepsis or necrotizing enterocolitis. Subgroup analysis was performed for ELBW and VLBW neonates.

Results A total of 239 neonates were included. We demonstrate a significantly increased risk of respiratory distress characterized by the need for ventilation (OR 1.045; Cl 1.0111.080) and surfactant administration (OR 1.050, Cl 1.0181.083) depending on the ACS-to-delivery interval irrespective of other confounders. Every additional day between ACS and delivery increased the risk for ventilation by $4.5 \%$ and for surfactant administration by $5 \%$. Subgroup analysis revealed sig- 
nificant differences of respiratory complications in VLBW infants.

Conclusions Our data strongly support the deliberate use and timing of antenatal corticosteroids in pregnancies with threatened preterm birth versus a liberal strategy. When given more than 7 days before birth, each day between application and delivery increases is relevant concerning major effects on the infant. Especially VLBW preterm neonates benefit from optimal timing.

\section{ZUSAMMENFASSUNG}

Introduction Die uneingeschränkte Gabe von antenatalen Kortikosteroiden (ACS) und der Zeitpunkt dieser Gabe stellen ein verbreitetes Problem in der Behandlung drohender Frühgeburten dar. Ziel dieser Studie war es, die unabhängige Wirkung pränataler Gaben von Kortikosteroiden zu unterschiedlichen Zeitpunkten auf die neonatalen Outcome-Parameter in einer Gruppe von Neugeborenen mit sehr niedrigem (verylow-birthweight, VLBW; 1000-1500 g) bzw. extrem niedrigem Geburtsgewicht (extremely-low-birthweight, ELBW; $<1000 \mathrm{~g}$ ) zu evaluieren. Wir stellten die Hypothese auf, dass ein langer Intervall zwischen ACS-Gabe und Geburt zu einem Ansteig der Atemwegskomplikationen führt.

Material und Methoden Die Hauptdatenquelle waren prospektive monozentrische Daten, die für das deutsche Überwachungssystem für nosokomiale Infektionen (KISS) in einem einzigen Zentrum zwischen 2015 und 2018 gesammelt wurden. Es wurde eine multivariate Regressionsanalyse durch- geführt, um die unabhängige Wirkung des Intervalls zwischen ACS-Gabe und Geburt auf den Bedarf nach künstlicher Beatmung bzw. einer Surfactant-Therapie sowie das Auftreten einer bronchopulmonalen Dysplasie, einer neonatalen Sepsis oder einer nekrotisierenden Enterokolitis zu bestimmen. Es wurden Untergruppenanalysen für die Gruppen der ELBWund der VLBW-Neugeborenen durchgeführt.

Ergebnisse Insgesamt wurden 239 Neugeborenen in die Studie aufgenommen. Wir fanden ein signifikant höheres Risiko für ein Atemnotsyndrom, das durch die Notwendigkeit einer mechanischen Beatmung (OR 1,045; KI 1,011-1,080) bzw. einer Surfactant-Gabe (OR 1,050, KI 1,018-1,083) gekennzeichnet war. Ungeachtet anderer Störfaktoren hing das Risiko von der Dauer des Intervalls zwischen ACS-Gabe und Geburt ab. Jeder zusätzliche Tag zwischen ACS-Gabe und Geburt erhöhte das Risiko für eine mechanische Beatmung um 4,5\% und für eine Surfactant-Therapie um 5\%. Die Untergruppenanalyse zeigte signifikante Unterschiede in den Atemwegskomplikationen bei VLBW-Neugeborenen.

Schlussfolgerungen Unsere Daten unterstreichen die Bedeutung, die ein bewusster Einsatz und das richtigen Timing von ACS-Gaben bei Schwangerschaften mit drohender Frühgeburt anstatt einer liberalen Strategie hat. Wenn die ACSGabe mehr als 7 Tage vor der Geburt erfolgt, kann jeder zusätzliche Tag zwischen ACS-Gabe und Geburt wichtige Auswirkungen auf das Neugeborene haben. Besonders VLBWFrühgeborene profitieren von einem optimalen Timing.

\section{Introduction}

Administration of antenatal corticosteroids (ACS) in threatened premature birth (PTB) before 34 weeks of gestation (wks) is stated to be the most effective treatment known for preventing serious preterm complications in the newborn including respiratory distress syndrome (RDS), intraventricular hemorrhage (IVH) and necrotizing enterocolitis (NEC), as well as reducing overall mortality $[1,2]$. Betamethasone $12 \mathrm{mg}$ twice or dexamethasone $4 \times 6 \mathrm{mg}$ decrease mortality and morbidity markedly for preterm infants especially in very low birthweight infants (VLBW < $1500 \mathrm{~g})[3,4]$. Data of extremely low birthweight infants (ELBW $<1000 \mathrm{~g}$ ) are still rare $[3,5,6]$. ACS enhances maturation of pulmonary structure and function $[1,7,8]$. Nevertheless, it is still unknown how long these beneficial effects last. There is evidence that the benefits of corticosteroids diminish over time. On the other hand the absence of ACS or incomplete ACS are risk factors for poor neonatal outcomes [9]. Current literature suggests a window of optimal efficacy between 48 hours and seven days after administration of the first dose of ACS [5,10-12]. Administration of a full course of ACS in PTB is recommended by worldwide guidelines [13-16], being used as a quality marker for delivery room practice despite the unpredictable nature of PTB, which leads to a liberal application of ACS to all PTB $[17,18]$. Currently, only 23 to $40 \%$ of ACS are administered in the window of optimal efficacy, which puts a large number of infants at risk for detrimental outcomes $[10,19,20]$.
The objective of this study was to evaluate the effects of ACSto-delivery interval on neonatal outcome parameters in a highrisk cohort of VLBW infants below 34 wks.

\section{Materials and Methods}

\section{Cohort composition}

From January 1, 2015 to December 31, 2018487 women were treated in the tertiary perinatal center of Jena university hospital because of threatened PTB before 34 wks. 248 women delivered after 34 wks or with a birthweight $>1500 \mathrm{~g}$ and were therefore excluded ( $\triangleright$ Fig. 1 ).

We included 239 inborn neonates with a birthweight $<1500 \mathrm{~g}$ and a GA $<34$ wks treated in our Neonatal Intensive Care Unit (NI$\mathrm{CU})$. Seven of those received no ACS, 47 received incomplete ACS and 185 received a complete course of ACS. A full course of ACS was defined as two doses of betamethasone with 24 hours in between doses and delivery at more than 48 hours after first dose. Only one dose or delivery before 48 hours after first dose was defined as incomplete course. Window of efficacy was defined as a delivery between $48 \mathrm{~h}$ and seven days after the first $12 \mathrm{mg}$ betamethasone dosage (group ACS $\leq 7$ days). The other group, out of this window, was defined as ACS $>7$ days. No rescue courses or multiple dose regimens were used in our institution. 


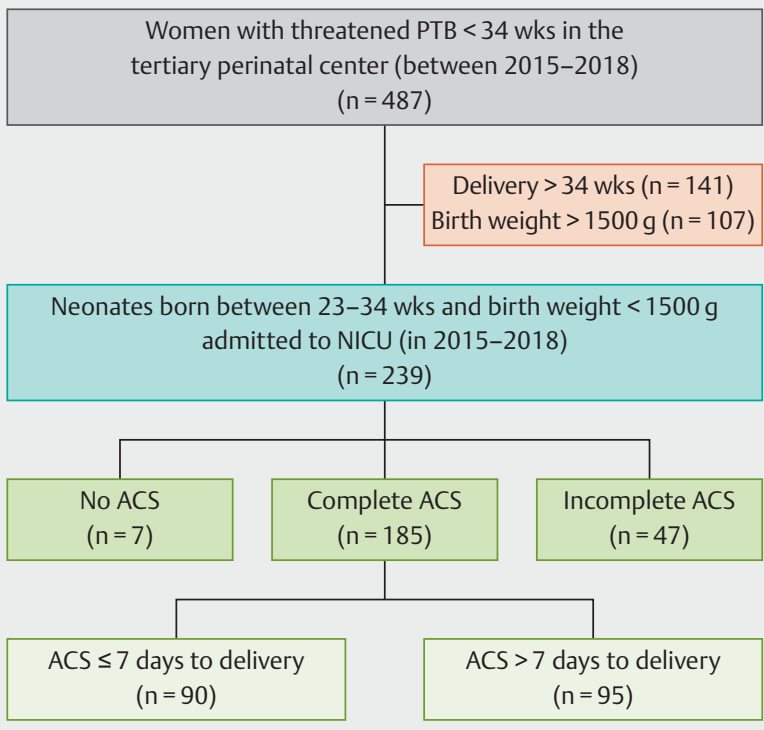

- Fig. 1 Cohort composition. Abbreviations: ACS - antenatal corticosteroids; NICU - neonatal intensive care unit; wks - weeks of gestation.

In the 185 cases of completed ACS neonatal outcomes were compared between those born $\leq 7$ days $(n=90)$ and those born $>7$ days after beginning of ACS $(n=95)$. To further differentiate concerning the effects of maturity and birthweight the cohort was stratified for ELBW (<1000 g) and VLBW (1000-1500 g) subgroups.

We do confirm that any research activities during this study were performed according to ethical standards of the Declaration of Helsinki and the protocol for this research project has been approved by the Ethics Committee of the Friedrich-Schiller-University.

\section{Ascertainment of clinical parameters and perinatal outcome}

The main source for neonatal parameters was the prospectively collected data for the German national nosocomial infection surveillance system, known as KISS (Krankenhaus-Infektions-Surveillance-System) and combined with clinical patient records retrospectively. KISS data were only entered by one of this study's investigators. Annual training and skill-tests for the investigators were ensured. Regular quality control meetings and reports from the KISS center secured data integrity. We assessed all infants $<1500 \mathrm{~g}$ birth weight up until either death or reaching a weight of $1800 \mathrm{~g}$. Parameters included were need for CPAP or need for surfactant via catheter or endotracheal tube and need for ventilation, as well as outcome parameters like mortality, neonatal sepsis, NEC and bronchopulmonary dysplasia (BPD) for neonatal complications and age at birth, fetal birthweight, singleton or multiple pregnancies. We decided to use objective parameters like ventilation and surfactant instead of the somewhat subjective radiographic interpretation of RDS [16].
Neonatal hypotrophy was defined as a birth weight below 10th percentile for gestational age or the Z-Score below - 1.282 according to the revised Fenton Preterm Growth Charts and is represented as small for gestational age (SGA) in the tables [21].

BPD was diagnosed based on Walsh criteria (need for supplemental oxygen or ventilation at 36/0 wks) [22] and NEC on NeoKISS criteria (German neonatal surveillance system) [23]. The infant morbidity was calculated using the CRIB-Score (Clinical Risk Index for Babies), which is a robust predictor of neonatal morbidity. It is a semiquantitative score that consists of six items (birthweight, gestational age [GA], severe malformation, neonatal acidosis and maximum and minimum oxygen requirements in the first 12 hours of life) with a minimum of zero and a maximum of 23 achievable points [24].

Pregnancy-related data including indication for delivery, mode of delivery and GA at birth were retrieved from our perinatal database. Diagnosis of delivery was grouped: 1st PTB caused by preterm premature rupture of membranes (PPROM) and/or chorioamnionitis; 2nd fetal growth restriction (FGR), 3rd maternal indications (e.g., pre-eclampsia, HELLP, placenta praevia) and 4th others (e.g., placental abruption). Mode of delivery included $\mathrm{C}$-section and any type of vaginal delivery.

\section{Statistical analysis}

For the main group comparison all inborn infants with GA $<34$ wks and birthweight $<1500 \mathrm{~g}$ were considered $(n=239)$. For the subgroup comparisons and multivariate logistic regression analysis we included only preterm infants after a full course of ACS $(n=185)$. In order to get unbiased estimates in the multivariate logistic regression model, a prior sample size estimation was performed for the primary outcome variables ventilation and surfactant use [25]. $x^{2}$ test or Fisher exact test were used to compare categorical data. Since most of the continuous data were not normally distributed, we used the median and interquartile range for data presentation and description. Mann-Whitney $U$ test or Kruskal-Wallis test were performed to compare continuous data between groups. Adjusted odds ratios (ORs) for estimating the association of the ACS-to-delivery interval (days) and gestational age at birth (wks) with neonatal complications (ventilation, surfactant, CPAP, BPD, neonatal sepsis and NEC) were determined using logistic regression. ORs with $95 \%$ confidence interval $(\mathrm{Cl})$ are presented. The potential confounders like fetal sex, birthweight and sepsis were included as covariates in the statistical analysis as presented in footnotes. Regression models were tested for an overall predictive value using Omnibus-Tests and only significant overall predictive models are presented [26]. A p-value $<0.05$ was considered to indicate statistical significance (2-tailed). Statistical analysis was performed with SPSS 24.0.

\section{Results}

Within the observation period, 346 of the 487 (71\%) women with threatened PTB and receiving ACS gave birth between 23/0 and $34 / 0$ wks. Although this rate is quite better than reported by others $[27,28]$ it means that in hindsight 135 women unnecessarily received ACS. 
A total of 239 neonates met our inclusion criteria (delivery in our hospital; NICU admission; born between 23/0 and 34/0 wks and a birth weight $<1500 \mathrm{~g}$ ), of which 185 received a complete course of ACS. Seven neonates did not receive ACS prior birth and 47 neonates received an incomplete ACS only. There was no significant difference between these groups regarding fetal sex, numbers of multiple pregnancies, gestational age at birth (weeks) and birth weight, but in the mode of delivery and delivery indications.

As expected, newborns with missing or incomplete ACS demonstrated more adverse outcomes with higher mortality, NEC rates and increasing need for invasive ventilation. The entire cohort characteristics and groups comparisons are presented in - Table 1.

\section{Multivariate logistic regression analysis for complete ACS with confounders}

Multivariate logistic regression analysis (including confounders: sex and birth weight) in the subgroup of complete ACS showed a significant effect of the ACS-to-delivery interval (time between first dose and delivery) on the need for ventilation (OR 1.045; CI 1.011-1.080) and surfactant administration (OR 1.050, Cl

- Table 1 Cohort characteristics and univariate analysis of the subgroups: no ACS, incomplete ACS and complete ACS ( $\leq 7$ days and > 7days).

\begin{tabular}{|c|c|c|c|c|c|c|c|}
\hline & $\begin{array}{l}\text { Entire } \\
\text { cohort }\end{array}$ & No ACS & $\begin{array}{l}\text { Incomplete } \\
\text { ACS }\end{array}$ & ACS $\leq 7$ days & ACS $>7$ days & p-value ${ }^{\dagger}$ & p-value $\ddagger$ \\
\hline Total, $\mathrm{n}$ & 239 & 7 & 47 & $90(48.6)$ & $95(51.4)$ & & \\
\hline \multicolumn{8}{|l|}{ Sex } \\
\hline - Male & $128(53.6)$ & $5(71.4)$ & $27(57.4)$ & $47(52.2)$ & $49(51.6)$ & 0.706 & 1 \\
\hline - Female & $111(46.4)$ & $2(28.6)$ & $20(42.6)$ & $43(47.8)$ & $46(48.4)$ & & \\
\hline Multiples & & & & & & 0.032 & 0.022 \\
\hline - Twins & $72(30.1)$ & $2(28.6)$ & $20(42.6)$ & $19(21.1)$ & $33(32.6)$ & & \\
\hline - Triplets & $4(1.7)$ & - & - & - & $4(4.2)$ & & \\
\hline Delivery indication & & & & & & $<0.001$ & 0.163 \\
\hline $\begin{array}{l}\text { - PPROM or } \\
\text { chorioamnionitis }\end{array}$ & $143(59.8)$ & $5(71.4)$ & $28(59.6)$ & $46(51.1)$ & $64(67.4)$ & & - \\
\hline $\begin{array}{l}\text { - Fetal growth } \\
\text { restriction }\end{array}$ & $49(20.5)$ & - & $2(4.3)$ & $28(31.1)$ & $19(20)$ & & - \\
\hline - Maternal indications & $26(10.9)$ & $1(14.3)$ & $6(12.8)$ & $11(12.2)$ & $8(8.4)$ & & - \\
\hline - Others & $21(8.8)$ & $1(14.3)$ & $11(23.4)$ & $5(5.6)$ & $4(4.2)$ & & - \\
\hline Mode of delivery & & & & & & 0.021 & 0.125 \\
\hline - Vaginal & $20(8.4)$ & $2(28.6)$ & $7(14.9)$ & $8(8.9)$ & $3(3.2)$ & & \\
\hline - C-Section & $219(91.6)$ & $5(71.4)$ & $40(85.1)$ & $82(91.1)$ & $98(96.8)$ & & \\
\hline Gestational age (weeks) & $28(26-30)$ & $27(26-32)$ & $26(25-29)$ & $28(26-30)$ & $29(27-30)$ & 0.002 & 0.042 \\
\hline $\begin{array}{l}\text { ACS-to-delivery interval } \\
\text { (days) }\end{array}$ & $5(2-12)$ & - & $1(1-2)$ & $4(3-5)$ & $17(10-26)$ & $<0.001$ & $<0.001$ \\
\hline Birth weight (g) & $\begin{array}{l}1020 \\
(790-1305)\end{array}$ & $\begin{array}{l}1030 \\
(855-1290)\end{array}$ & $\begin{array}{l}945 \\
(750-1310)\end{array}$ & $\begin{array}{l}950 \\
(683.75-1245)\end{array}$ & $\begin{array}{l}1180 \\
(935-1385)\end{array}$ & 0.003 & $<0.001$ \\
\hline SGA & $56(23.4)$ & $3(42.9)$ & $7(14.9)$ & $28(31.1)$ & $18(18.9)$ & 0.060 & 0.063 \\
\hline CPAP & $226(95.4)$ & $6(85.7)$ & $42(91.3)$ & $84(94.4)$ & 94 (98.9) & 0.105 & 0.109 \\
\hline Surfactant & $150(63.3)$ & $5(71.4)$ & $32(69.6)$ & $53(59.6)$ & $60(63.2)$ & 0.679 & 0.651 \\
\hline Ventilation & $76(32.2)$ & $3(42.9)$ & $23(50)$ & $21(23.6)$ & $29(30.9)$ & 0.017 & 0.320 \\
\hline Sepsis & $21(8.8)$ & - & $3(6.4)$ & $14(15.6)$ & $4(4.3)$ & 0.036 & 0.012 \\
\hline NEC & $12(5)$ & - & $6(12.8)$ & $5(5.6)$ & $1(1.1)$ & 0.025 & 0.112 \\
\hline BPD & $27(11.3)$ & $1(14.3)$ & $4(8.5)$ & $15(16.7)$ & $7(7.4)$ & 0.214 & 0.068 \\
\hline Neonatal death & $18(7.5)$ & $2(28.6)$ & $7(14.9)$ & $7(7.8)$ & $2(2.1)$ & 0.007 & 0.093 \\
\hline CRIB-Score & $2(1-7)$ & $6(1-15)$ & $3(1-7.25)$ & $2(1-7)$ & $1(1-5)$ & 0.003 & 0.013 \\
\hline $\begin{array}{l}\text { Data are } \mathrm{n}(\%) \text { or median } \\
{ }^{\dagger} \text { Comparison between th } \\
\ddagger \text { Comparison } \mathrm{ACS} \leq 7 \text { day }\end{array}$ & $\begin{array}{l}\text { interquartile rar } \\
\text { ur groups. } \\
\text { a } A C S>7 \text { days o }\end{array}$ & $(I Q R)$ unless oth & vise specified. Si & icant findings ( $p<$ & are highlighted & bold. & \\
\hline \multicolumn{8}{|c|}{$\begin{array}{l}\text { ACS - antenatal corticosteroids; PPROM - preterm premature rupture of membranes; CPAP - continuous positive airway pressure; } \\
\text { SGA - small for gestational age; NEC - necrotizing enterocolitis; BPD - bronchopulmonary dysplasia; CRIB- clinical risk index for babies }\end{array}$} \\
\hline
\end{tabular}


- Table 2 Multivariate regression analysis of the association of ACS-to-delivery, gestational age and neonatal complications.

\begin{tabular}{|c|c|c|c|c|c|}
\hline Outcome variable & Influencing variable & Adjusted ORs* & $\mathrm{Cl}(95 \%)$ & Adjusted ORs $\dagger$ & $\mathrm{Cl}(95 \%)$ \\
\hline \multirow[t]{2}{*}{ Ventilation $(n=183)$} & ACS-to-delivery interval (days) & 1.045 & $1.011-1.080$ & 1.048 & $1.013-1.084$ \\
\hline & Gestational age (weeks) & 0.604 & $0.466-0.783$ & 0.592 & $0.454-0.772$ \\
\hline \multirow[t]{2}{*}{ Surfactant $(n=184)$} & ACS-to-delivery interval (days) & 1.050 & $1.018-1.083$ & 1.050 & $1.018-1.083$ \\
\hline & Gestational age (weeks) & 0.544 & $0.426-0.695$ & 0.545 & $0.427-0.696$ \\
\hline \multirow[t]{2}{*}{$\operatorname{BPD}(n=185)$} & ACS-to-delivery interval (days) & 1.032 & 0.970-1.099 & 1.026 & $0.958-1.097$ \\
\hline & Gestational age (weeks) & 0.684 & $0.479-0.977$ & 0.657 & $0.440-0.979$ \\
\hline \multirow[t]{2}{*}{ Sepsis $(n=184)$} & ACS-to-delivery interval (days) & 0.948 & $0.860-1.045$ & & \\
\hline & Gestational age (weeks) & 0.961 & $0.689-1.341$ & & \\
\hline \multirow[t]{2}{*}{$\operatorname{NEC}(n=184)$} & ACS-to-delivery interval (days) & 0.834 & $0.613-1.135$ & 0.824 & $0.596-1.141$ \\
\hline & Gestational age (weeks) & 1.240 & $0.734-2.097$ & 1.369 & $0.775-2.418$ \\
\hline
\end{tabular}

1.018-1.083) as shown in $>$ Table 2 . When looking at the subgroup of complete ACS within the window of efficacy no significant independent effect of ACS-to-delivery interval could be demonstrated for the need for ventilation (OR 1.065; CI 0.724-1.566) nor for surfactant administration (OR 1.290; Cl 0.874-1.904). Each additional day between ACS and delivery increased the risk for ventilation by $4.5 \%$ and surfactant by $5 \%$ despite all the other confounders.

Gestational age at birth also revealed an independent impact on the need for ventilation (OR 0.604, $\mathrm{Cl} 0.466-0.783$ ) and for surfactant use (OR $0.544 \mathrm{Cl} 0.426-0.695)$ as well as for BPD (OR 0.684; CI 0.479-0.977). Each additional week of intrauterine maturation decreased the risk for ventilation by $38 \%$, for surfactant application by $47 \%$ and for the occurrence of BPD by $31 \%$ as expected. Adding sepsis as a potential confounder as presented in the right column of $\boldsymbol{\nabla}$ Table $\mathbf{2}$ did not affect prior results.

\section{Univariate analysis: Comparison of complete ACS $\leq 7$ days vs. ACS $>7$ days}

Timing of ACS was within the window of efficacy in 48.6\% ( $n=90)$ of the cases (ACS $\leq 7$ days). Both subgroups ACS $\leq 7$ days and ACS $>7$ days did not differ in fetal sex, delivery indications and mode of delivery but were significantly different in GA (28 wks [IQR 26-39] vs. 29 wks [IQR 27-30]; $\mathrm{p}<0.05$ ), birth weight (950 g [IQR 838.75-1245] vs. $1180 \mathrm{~g}$ [IQR 935-1385]; $\mathrm{p}<0.01$ ) and CRIBScore (2 [IQR 1-7] vs. 1 [IQR 1-5]; $\mathrm{p}<0.05)$. Less multiples were seen in the group with ACS $\leq 7$ days $(21.1 \%$ vs. $36.6 \%$; $p<0.05)$.

The timing of ACS showed a strong trend towards the need for less CPAP, surfactant, and ventilation in the subgroup ACS $\leq 7$ days. No statistically significant effect was seen on the incidence of NEC, BPD or neonatal death. Remarkably, there were more cases of neonatal sepsis $(15.6 \%$ vs. $4.3 \%$; $p<0.05)$ in the group with ACS $\leq 7$ days compared to the group with ACS $>7$ days ( Table 1).

\section{Univariate analysis of complete ACS: VLBW and ELBW subgroups}

To countervail the birthweight discrepancies in the main group, a subgroup analysis was performed comparing ELBW and VLBW infants ( $\triangleright$ Table 3 ). Within these groups the efficacy of ACS timing was evaluated. The mean intervals between ACS and delivery were significantly different when comparing ACS $\leq 7$ days and ACS $>7$ days in all subgroups.

In the VLBW subgroup (birthweight 1000-1500 g) ACS $\leq 7$ days reduced the risk for a RDS with a reduced need for surfactant application ( $26.3 \%$ vs. $54.7 \%$; $<0.01)$ and for ventilation $(5.3 \%$ vs. $25.0 \%$; $<0.05$ ) significantly. In the VLBW group there were significant differences concerning the indication for delivery, because more children in the ACS $\leq 7$ days group were treated for FGR $(28.2 \%$ vs. $15.6 \%)$ whereas more cases of PPROM (41.0\% vs. $70.3 \%$; $p>0.05$ ) and multiples (23.1\% vs. $46.9 \%$ ) could be seen in the ACS $>7$ days group. We did not see differences in neonatal complications: death, BPD, NEC and sepsis in both subgroups. In the ELWB subgroup $<1000 \mathrm{~g}(\mathrm{n}=82)$ no differences of patient characteristics, indications, nor perinatal complications could be found. There was again a trend towards the need for less mechanical ventilation in the ACS $\leq 7$ days subgroup.

A visualization of the cohort and the main respiratory complications (surfactant use and mechanical ventilation) is summarized in > Fig. 2, according to birthweight and ACS-to-delivery interval. The scatter plots show in a case by case manner the higher percentage of interventions (e.g. more green dots) in the ACS $>7$ days group (right upper quadrant) in VLBW infants (1000-1499 g - right quadrant) than in the ACS $<7$ days group (right lower quadrant).

\section{Discussion}

This analysis of a large well characterized cohort of high-risk preterm neonates below $1500 \mathrm{~g}$ birthweight could demonstrate a significantly increased risk of severe RDS characterized by the need for ventilation (OR 1.045; Cl 1.011-1.080) and surfactant 
- Table 3 Comparison of the subgroups ACS $\leq 7$ days and ACS > 7 days depending on birthweight categories: ELBW and VLBW.

\begin{tabular}{|c|c|c|c|c|c|c|}
\hline \multirow[b]{2}{*}{ Variable } & \multicolumn{3}{|c|}{ ELBW $<1000 \mathrm{~g}$} & \multicolumn{3}{|c|}{ VLBW $\geq 1000-1500 \mathrm{~g}$} \\
\hline & $\mathrm{ACS} \leq 7$ days & ACS $>7$ days & p-value ${ }^{\dagger}$ & ACS $\leq 7$ days & ACS $>7$ days & p-value $^{\dagger}$ \\
\hline Total, $\mathrm{n}$ & 51 & 31 & & 39 & 64 & \\
\hline Sex & & & 0.820 & & & 0.1 \\
\hline - Male & $27(52.9)$ & $15(48.4)$ & & $20(51.3)$ & $34(53.1)$ & \\
\hline - Female & $24(47.1)$ & $16(51.6)$ & & $19(48.7)$ & $30(46.9)$ & \\
\hline \multicolumn{7}{|l|}{ Multiples } \\
\hline - Twins & $10(19.6)$ & $5(16.1)$ & 0.775 & $9(23.1)$ & $26(40.6)$ & 0.033 \\
\hline - Triplets & & & & - & $4(6.3)$ & \\
\hline Delivery indication & & & 0.966 & & & 0.033 \\
\hline - PPROM or chorioamnionitis & $30(58.8)$ & $19(61.3)$ & & $16(41.0)$ & $45(70.3)$ & \\
\hline - Fetal growth restriction & $17(33.3)$ & $9(29.0)$ & & $11(28.2)$ & $10(15.6)$ & \\
\hline - Maternal indications & $3(5.9)$ & $2(6.5)$ & & $8(20.5)$ & $6(9.4)$ & \\
\hline - Others & $1(2)$ & $1(3.2)$ & & $4(10.3)$ & $3(4.7)$ & \\
\hline - Mode of delivery & & & 0.245 & & & 0.632 \\
\hline - Vaginal & $6(11.8)$ & $1(3.2)$ & & $2(5.1)$ & $2(3.1)$ & \\
\hline - C-Section & $45(88.2)$ & $30(96.8)$ & & $37(94.9)$ & $62(96.9)$ & \\
\hline Gestational age (weeks) & $26(24-27)$ & $27(25-27)$ & 0.215 & $30(29-32)$ & $29(29-30)$ & 0.112 \\
\hline ACS-to-delivery interval (days) & $4(3-5)$ & $13(10-22)$ & $<0.001$ & $4(3-5)$ & $20.5(10-32)$ & $<0.001$ \\
\hline Birth weight (g) & $\begin{array}{l}720 \\
(550-920)\end{array}$ & $\begin{array}{l}840 \\
(675-935)\end{array}$ & 0.074 & $\begin{array}{l}1290 \\
(1150-1384)\end{array}$ & $\begin{array}{l}1295 \\
(1172.5-1427.5)\end{array}$ & 0.509 \\
\hline SGA & $17(33.3)$ & $7(22.6)$ & 0.330 & $11(28.2)$ & $11(17.2)$ & 0.219 \\
\hline CPAP & $47(92.2)$ & $31(100)$ & 0.292 & $37(97.4)$ & $63(98.4)$ & 1 \\
\hline Surfactant & $43(84.3)$ & $25(80.6)$ & 0.765 & $10(26.3)$ & $35(54.7)$ & 0.007 \\
\hline Ventilation & $19(37.3)$ & $13(43.3)$ & 0.642 & $2(5.3)$ & $16(25)$ & 0.014 \\
\hline Sepsis & $11(21.6)$ & $4(13.3)$ & 0.555 & $3(7.7)$ & - & 0.052 \\
\hline NEC & $4(7.8)$ & $1(3)$ & 0.646 & $1(2.6)$ & - & 0.379 \\
\hline BPD & $13(25.5)$ & $6(19.4)$ & 0.598 & $2(5.1)$ & $1(1.6)$ & 0.555 \\
\hline Neonatal death & $6(11.8)$ & 0 & 0.078 & $1(2.6)$ & $2(3.1)$ & 1 \\
\hline CRIB-Score & $6(2-9)$ & $7(2-8)$ & 0.535 & $1(0-2)$ & $1(0-2)$ & 0.884 \\
\hline \multicolumn{7}{|c|}{$\begin{array}{l}\text { ACS - antenatal corticosteroids; ELBW - extreme low birthweight; VLBW - very low birthweight; PPROM - preterm premature rupture of membranes; } \\
\text { SGA - small for gestational age; CPAP - continuous positive airway pressure; NEC - necrotizing enterocolitis; BPD - bronchopulmonary dysplasia, } \\
\text { CRIB - clinical risk index for babies }\end{array}$} \\
\hline
\end{tabular}

administration (OR 1.050; $\mathrm{Cl}$ 1.018-1.083) depending on the ACS-to-delivery interval irrespective of other confounders. Every additional day between ACS and delivery increased the risk for ventilation by $4.5 \%$ and for surfactant administration by $5 \%$ in our cohort ( $\vee$ Fig. 2). However, this could not be shown when the delivery occurred within 7 days in the window of optimal efficacy. Additionally, every week of maturation decreased the risk of pulmonary complications. This finding emphasizes the importance of a careful timing as close to delivery as possible versus a liberal use of ACS in all PTB. We focused on the patient group of ELBW and VLBW infants as those are at the highest risk of complications and long-term sequelae due to their immaturity $[23,29,30]$.

Our results also confirm previous data $[3,4]$ and demonstrate that a completed course of ACS reduces neonatal mortality by
$83 \%$ compared to no ACS and by $67 \%$ compared to an incomplete ACS course. We also report a significant reduction of NEC and the need for ventilation as shown in $\mathbf{~ T a b l e ~} \mathbf{1}$ in agreement to recent studies and meta-analysis [1,3,31]. This underlines the need and benefits of a full course of ACS before the delivery of a preterm infant whenever possible.

In the univariate analysis, reduced respiratory complications could be seen as a strong trend but failed to reach statistical significance. Remarkably, the group ACS $\leq 7$ days comprised infants were born in mean 9 days earlier ( 28 wks vs. 29 wks; $p<0.05$ ), with lower BW (950 g vs. $1180 \mathrm{~g} ; \mathrm{p}<0.01)$ and seen to be sicker (CRIB Score 2 vs. 1 ; $p<0.05$ ) than in the group ACS $>7$ days, which are all known risk factors for respiratory complications. This imbalance could be a limitation due to the retrospective character of 

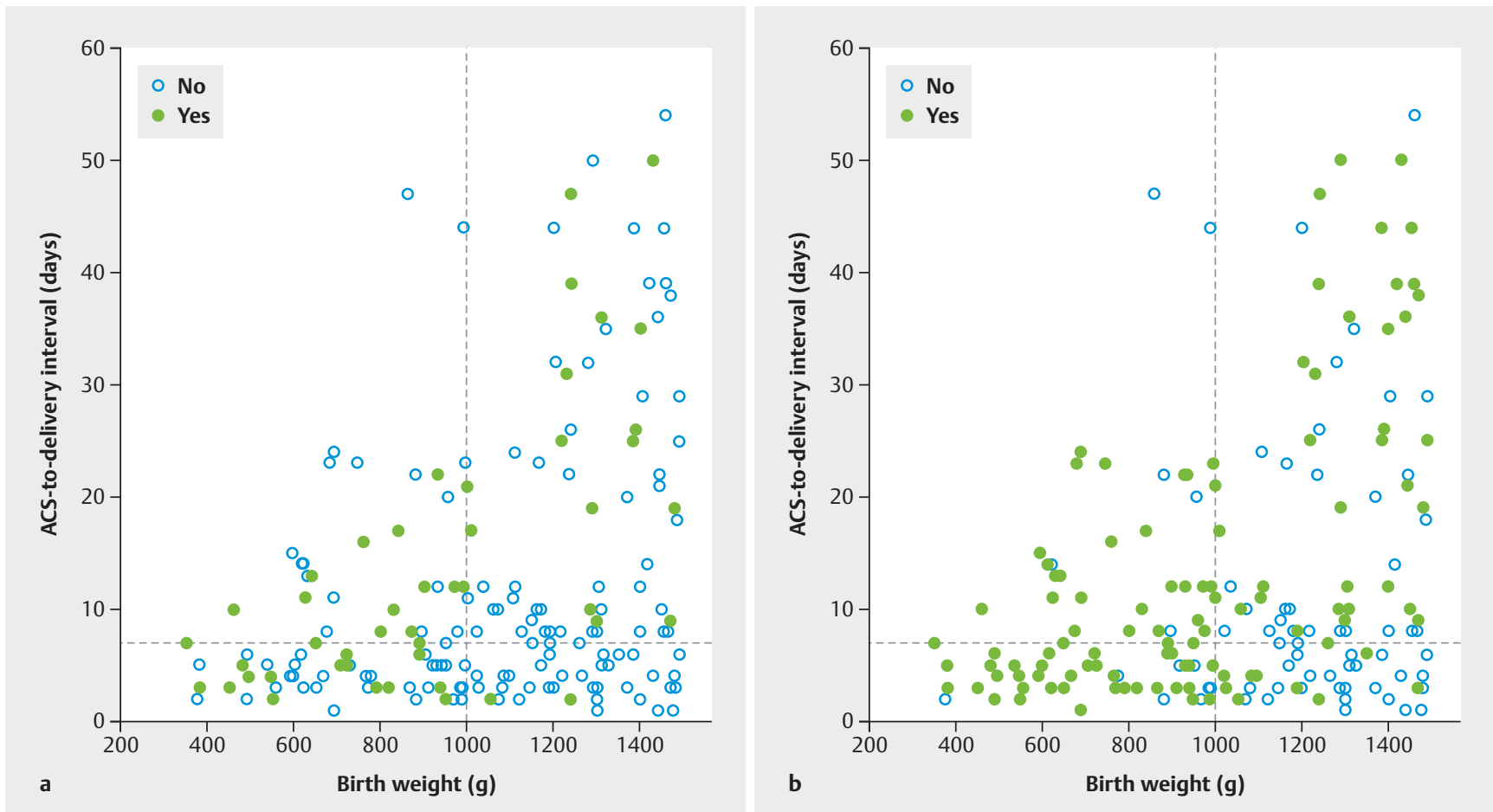

- Fig. 2 Scatterplots of respiratory complications (a mechanical ventilation, b surfactant use) matched to birthweight and ACS-to-delivery interval, horizontal line at 7 days of ACS-to-delivery interval, vertical line at birthweight of 1000 grams. Empty plots mean no complication, full plots mean complication occurred. Abbreviations: ACS - antenatal corticosteroids.

the analysis, which is not stratified to GA of ACS prophylaxis. There were also more cases of FGR in the group ACS $\leq 7$ days $(31.1 \%$ vs. $20 \%)$. Neonatal sepsis occurred more often when ACS was given within 7 days to birth. Lower GA, lower BW and FGR are individual risk factors for neonatal sepsis, which seems to be a possible explanation for this effect in our cohort [23, 32]. FGR fetuses were excluded from most studies [3,32] since it is hypothesized that higher catecholamine and steroid levels due to the fetal stress in FGR flatten the ACS effect [33].

A subgroup analysis according to birthweight $<1000 \mathrm{~g}$ (ELBW) and 1000-1500 g (VLBW) showed that VLBW infants did need significantly less ventilation ( $5.3 \%$ vs. $25 \%$; $p<0.05)$ and surfactant ( $26.3 \%$ vs. $54.7 \%$; $p<0.01$ ) if they were born within 7 day after ACS. We were able to show this positive effect in the group ACS $\leq 7$ days, although FGR is known to be a risk factor for pulmonary complications [3, 32, 34] and the distribution of neonates with hypotrophy in the two groups was somewhat unbalanced (28.2\% vs. $17.2 \%$, but n. s.). Adding hypotrophy as an independent risk factor to the multivariate regression did not change the results of our analysis concerning the effect of the ACS-to-delivery interval. Nevertheless, our results must be interpreted cautiously because of a higher rate of PPROM cases (41 vs. $70.3 \%$; $p<0.05$ ) in the VLBW group, albeit not neonatal sepsis (VLBW $7.7 \%$ vs. $0 \%$; n.s.). Our data consistently showed a strong trend towards less severe RDS as seen in less need for ventilation in the ELBW group with timely ACS but failed to reach statistical significance. Nearly all infants needed surfactant therapy initially independent of ACS timing in this subgroup. These infants are in the highest risk group for neonatal complications (median age both 26 vs. 27 wks and median weight 720 vs. $840 \mathrm{~g}$ ) but constitute a major part of our study population (82/185 infants). It is still unclear to what extent these extremely premature infants benefit from ACS. An explanation for the uncertain effect of ACS on outcome could be the extreme immaturity of the pulmonary system [3,35]. Additionally, the multitude of treatment options in NICU treatment nowadays may reduce the prominent effectiveness of ACS [16]. Our findings suggest that these infants also seem to benefit from a timely ACS administration, adding valuable data for extremely premature infants $[3,5,6]$.

One strength of our study is the large number of VLBW and ELBW infants for which data is rare and treatment algorithms are still unclear. As a single center study, we do have high-quality data records, clear treatment algorithms by SOP and therefore little intra-operator variability. Nevertheless, the knowledge about ACS administration might have biased the treatment of infants. To account for these problems objective parameters like need of ventilation and surfactant use were considered. The non-randomized character of the study caused imbalances in the group composition, which we could partially countervail by stratified subgroup analysis. This could limit the generalizability of our results to other delivery populations.

These limitations can only be overcome by a randomized controlled trial to verify these results, but this seems ethically questionable from our point of view. 


\section{Conclusion}

In conclusion, our data strongly support the deliberate use and timing of ACS in women at risk of preterm birth in contrast to unrestricted ACS administration as scattershot. Quality improvement measures should therefore focus on administration of ACS within the window of efficacy instead of administration of ACS to every woman with threatened PTB. Each additional day in between ACS and delivery is relevant concerning major effects on the infant. VLBW infants especially seem to profit from ACS in the window of efficacy concerning respiratory complications. Since prospective studies on ACS seem not ethically feasible, we believe that our results based on prospective collected register data (KISS) are of high value.

\section{Acknowledgements}

The authors acknowledge the obstetric and neonatal team for their support and contribution to data collection.

\section{Conflict of Interest}

The authors declare that they have no conflict of interest.

\section{References}

[1] Stavropoulou D, Hentschel R. [Antenatal Steroid Therapy in Threatened Premature Birth - State of the Art]. Z Geburtshilfe Neonatol 2017; 221: 265-271. doi:10.1055/s-0043-116016

[2] Schleussner $E$. The prevention, diagnosis and treatment of premature labor. Dtsch Arztebl Int 2013; 110: 227-235; quiz 236. doi:10.3238/arztebl.2013.0227

[3] Roberts D, Brown J, Medley N et al. Antenatal corticosteroids for accelerating fetal lung maturation for women at risk of preterm birth. Cochrane Database Syst Rev 2017; (3): CD004454. doi:10.1002/14651858. CD004454.pub3

[4] Jobe AH, Soll RF. Choice and dose of corticosteroid for antenatal treatments. Am J Obstet Gynecol 2004; 190: 878-881. doi:10.1016/j. ajog.2004.01.044

[5] Crowley PA. Antenatal corticosteroid therapy: a meta-analysis of the randomized trials, 1972 to 1994. Am J Obstet Gynecol 1995; 173: 322335. doi:10.1016/0002-9378(95)90222-8

[6] Travers CP, Carlo WA, McDonald SA et al.; Eunice Kennedy Shriver National Institute of Child Health and Human Development Neonatal Research Network. Mortality and pulmonary outcomes of extremely preterm infants exposed to antenatal corticosteroids. Am J Obstet Gynecol 2018; 218: 130.e1-130.e13. doi:10.1016/j.ajog.2017.11.554

[7] Ballard PL, Ballard RA. Scientific basis and therapeutic regimens for use of antenatal glucocorticoids. Am J Obstet Gynecol 1995; 173: 254-262

[8] Bolt RJ, van Weissenbruch MM, Lafeber HN et al. Glucocorticoids and lung development in the fetus and preterm infant. Pediatr Pulmonol 2001; 32: 76-91

[9] [Anonym]. Effect of corticosteroids for fetal maturation on perinatal outcomes. NIH Consensus Development Panel on the Effect of Corticosteroids for Fetal Maturation on Perinatal Outcomes. JAMA 1995; 273 : 413-418. doi:10.1001/jama.1995.03520290065031

[10] Lau HCQ, Tung JSZ, Wong TTC et al. Timing of antenatal steroids exposure and its effects on neonates. Arch Gynecol Obstet 2017; 296: 10911096. doi:10.1007/s00404-017-4543-1
[11] Crowther CA, McKinlay C], Middleton P et al. Repeat doses of prenatal corticosteroids for women at risk of preterm birth for improving neonatal health outcomes. Cochrane Database Syst Rev 2015; 2015 (7): CD003935. doi:10.1002/14651858.CD003935.pub4

[12] Vidaeff AC, Ramin SM, Gilstrap LC 3rd et al. Characterization of corticosteroid redosing in an in vitro cell line model. Am J Obstet Gynecol 2004; 191: 1403-1408. doi:10.1016/j.ajog.2004.06.049

[13] Vermillion ST, Soper DE, Newman RB. Is betamethasone effective longer than 7 days after treatment? Obstet Gynecol 2001; 97: 491-493. doi:10.1016/s0029-7844(00)01178-9

[14] Ring AM, Garland JS, Stafeil BR et al. The effect of a prolonged time interval between antenatal corticosteroid administration and delivery on outcomes in preterm neonates: a cohort study. Am J Obstet Gynecol 2007; 196: 457.e1-6. doi:10.1016/j.ajog.2006.12.018

[15] Sehdev HM, Abbasi S, Robertson P et al. The effects of the time interval from antenatal corticosteroid exposure to delivery on neonatal outcome of very low birth weight infants. Am J Obstet Gynecol 2004; 191: 14091413. doi:10.1016/j.ajog.2004.06.055

[16] Peaceman AM, Bajaj K, Kumar P et al. The interval between a single course of antenatal steroids and delivery and its association with neonatal outcomes. Am J Obstet Gynecol 2005; 193: 1165-1169. doi:10.1016/j.ajog.2005.06.050

[17] van Baaren G], Vis JY, Wilms FF et al. Predictive value of cervical length measurement and fibronectin testing in threatened preterm labor. Obstet Gynecol 2014; 123: 1185-1192. doi:10.1097| AOG.0000000000000229

[18] McPheeters ML, Miller WC, Hartmann KE et al. The epidemiology of threatened preterm labor: a prospective cohort study. Am J Obstet Gynecol 2005; 192: 1325-1329; discussion 1329-1330. doi:10.1016/j. ajog.2004.12.055

[19] Levin HI, Ananth CV, Benjamin-Boamah C et al. Clinical indication and timing of antenatal corticosteroid administration at a single centre. BJOG 2016; 123: 409-414. doi:10.1111/1471-0528.13730

[20] Razaz N, Skoll A, Fahey J et al. Trends in optimal, suboptimal, and questionably appropriate receipt of antenatal corticosteroid prophylaxis. Obstet Gynecol 2015; 125: 288-296. doi:10.1097/ AOG.0000000000000629

[21] Fenton TR, Kim JH. A systematic review and meta-analysis to revise the Fenton growth chart for preterm infants. BMC Pediatrics 2013; 13: 59. doi:10.1186/1471-2431-13-59

[22] Walsh MC, Yao Q, Gettner P et al. Impact of a physiologic definition on bronchopulmonary dysplasia rates. Pediatrics 2004; 114: 1305-1311. doi:10.1542/peds.2004-0204

[23] Leistner R, Piening B, Gastmeier P et al. Nosocomial Infections in Very Low Birthweight Infants in Germany: Current Data from the National Surveillance System NEO-KISS. Klin Padiatr 2013; 225: 75-80. doi:10.1055/s-0033-1334886

[24] Sarquis AL, Miyaki M, Cat MN. [The use of CRIB score for predicting neonatal mortality risk]. J Pediatr (Rio J) 2002; 78: 225-229

[25] Peduzzi P, Concato J, Kemper E et al. A simulation study of the number of events per variable in logistic regression analysis. J Clin Epidemiol 1996; 49: 1373-1379. doi:10.1016/s0895-4356(96)00236-3

[26] Hušková M, Meintanis SG. Omnibus tests for the error distribution in the linear regression model. Statistics 2007; 41: 363-376. doi:10.1080/ 02331880701442643

[27] Carreno CA, Refuerzo JS, Holland MG et al. The Frequency of Prior Antenatal Corticosteroid Therapy in Late Preterm Birth Pregnancies. Am J Perinatol 2011; 28: 767-772. doi:10.1055/s-0031-1280858

[28] Boßung V, Rody A. Eine Frage des Timings: Retrospektive 10-Jahres-Analyse zur RDS-Prophylaxe bei Frühgeburten vor $34+0$ SSW. Geburtshilfe Frauenheilkd 2018; 78: 238. doi:10.1055/s-0038-1671481 
[29] Langhammer K, Roth B, Kribs A et al. Treatment and outcome data of very low birth weight infants treated with less invasive surfactant administration in comparison to intubation and mechanical ventilation in the clinical setting of a cross-sectional observational multicenter study. Eur J Pediatr 2018; 177: 1207-1217. doi:10.1007/s00431-018-3179-x

[30] Hartel C, Paul P, Hanke K et al. Less invasive surfactant administration and complications of preterm birth. Sci Rep 2018; 8: 8333. doi:10.1038/s41598-018-26437-x

[31] Deshmukh M, Patole S. Antenatal corticosteroids for neonates born before 25 Weeks-A systematic review and meta-analysis. PLoS One 2017; 12: e0176090. doi:10.1371/journal.pone.0176090

[32] Bernstein IM, Horbar JD, Badger G] et al. Morbidity and mortality among very-low-birth-weight neonates with intrauterine growth restriction. Am J Obstet Gynecol 2000; 182: 198-206. doi:10.1016/s0002-9378 (00)70513-8
[33] Torrance HL, Derks JB, Scherjon SA et al. Is antenatal steroid treatment effective in preterm IUGR fetuses? Acta Obstet Gynecol Scand 2009; 88: 1068-1073. doi:10.1080/00016340903176784

[34] Morrison JL, Botting KJ, Soo PS et al. Antenatal steroids and the IUGR fetus: are exposure and physiological effects on the lung and cardiovascular system the same as in normally grown fetuses? J Pregnancy 2012; 2012: 839656. doi:10.1155/2012/839656

[35] Onland W, de Laat MW, Mol BW et al. Effects of antenatal corticosteroids given prior to 26 weeks' gestation: a systematic review of randomized controlled trials. Am J Perinatol 2011; 28: 33-44. doi:10.1055/s-00301262509 